\title{
Uso do BIM para a gestão de riscos em empreendimentos de infraestrutura no Brasil
}

\section{Use of BIM for risk management in infrastructure projects in Brazil}

\section{Ana Beatriz Perrone Fernandes}

Universidade de São Paulo | São Paulo | Brasil | beatriz_fernandes@usp.br

\section{Guilherme Borges de Lima}

Universidade de São Paulo | São Paulo | Brasil | guilherme_borges@usp.br

\section{Ludmila Souza Vieira}

Universidade de São Paulo | São Paulo | Brasil | ludmila.vieira@usp.br

\section{Márcio Rômulo da Silva Regis}

Universidade de São Paulo | São Paulo | Brasil | mromulosregis@usp.br

\section{Eduardo Toledo Santos}

Universidade de São Paulo | São Paulo | Brasil | etoledo@usp.br

\section{Flavia Rodrigues de Souza}

Universidade de São Paulo | São Paulo | Brasil | flavia.souza@usp.br

Lúcia Helena Oliveira

Universidade de São Paulo | São Paulo | Brasil | lucia.helena@usp.br

\section{Sérgio Leal Ferreira}

Universidade de São Paulo | São Paulo | Brasil | sergio.leal@usp.br

\section{Silvio Burrattino Melhado}

Universidade de São Paulo | São Paulo | Brasil | silvio.melhado@usp.br

\section{Resumo}

Embora o BIM (Building Information Modelling) possa apoiar a gestão de riscos (GR) na construção civil, o BIM e a GR estão em estágio inicial de adoção no Brasil. Neste trabalho investigou-se a percepção dos profissionais sobre o uso do BIM associado à $G R$ em empreendimentos de infraestrutura, devido à sua especial exposição a riscos. Foi realizado um levantamento, mediante questionário, obtendo-se um panorama sobre os usos, benefícios e barreiras para implementação das metodologias. Identificaram-se as áreas favorecidas pelo uso do BIM na GR e as barreiras a superar, tendo em vista a obtenção dos benefícios nesses empreendimentos.

Palavras-chave: BIM. Gestão de riscos. Empreendimentos de infraestrutura. 


\begin{abstract}
Although BIM (Building Information Modeling) can support risk management (RM) in civil construction, BIM and RM are in the early stages of adoption in Brazil. This work investigated the perception of professionals about the use of BIM associated with RM in infrastructure projects, due to their special exposure to risks. A survey was carried out through a questionnaire, obtaining an overview of the uses, benefits and barriers for the implementation of the methodologies. The areas favored by the use of BIM in the RM and the barriers to be overcome were identified, aiming to obtain the benefits in these projects.
\end{abstract}

Keywords: BIM. Risk management. Infrastructure projects.

\title{
INTRODUÇÃO
}

Apesar dos esforços empreendidos nas esferas pública e privada [1] [2] [3], o BIM (Building Information Modelling) ainda se encontra em um estágio inicial de adoção no Brasil [4]. Mesmo com o aumento da disseminação da metodologia, as terminologias e conceitos do BIM parecem desconhecidos a muitos dos profissionais do meio [5]. Essa falta de entendimento faz com que potenciais usuários não conheçam os benefícios que poderiam usufruir, caso o BIM fosse implementado em seus empreendimentos.

A indústria da construção civil se caracteriza por empreendimentos únicos, concebidos para condições particulares de entrega e cujo ciclo de produção, reiniciado a cada novo produto, é influenciado por diversas variáveis e especificidades referentes ao local de execução. A complexidade e variabilidade que cercam um empreendimento da construção civil resulta nas incertezas presentes durante o seu ciclo de vida. Os riscos decorrem de tais incertezas, como o resultado de eventos que podem impactar negativamente (ameaças) ou positivamente (oportunidades) o alcance dos objetivos do empreendimento [6].

Dado que os riscos não podem ser completamente evitados e que a limitação de recursos é inerente a qualquer projeto, para que um empreendimento da construção civil atinja seus objetivos é necessário que os riscos envolvidos sejam adequadamente geridos [7], possibilitando, inclusive, agregar valor ao produto final [8].

Apesar de sua importância, a indústria da construção tem apresentado déficit em relação à gestão de riscos (GR) de seus empreendimentos, o que causa grandes falhas em relação ao cumprimento de prazos, orçamento e qualidade dos produtos entregues [9]. Técnicas de GR são aplicadas de forma ainda incipiente na indústria da construção brasileira, limitando-se, em geral, a empresas de grande porte [10].

Idealmente, a gestão de riscos deve englobar todo o ciclo de vida do empreendimento. Em cada fase, são definidos responsáveis, técnicas e resultados esperados, levando-se em conta o nível de desenvolvimento e as demandas das partes interessadas [11]. Para que as informações não sejam perdidas entre as fases, é fundamental o uso de uma metodologia que permita o registro adequado, por meio do emprego de tecnologias da informação. Nesse sentido, ao possibilitar a incorporação desse registro ao próprio modelo, o BIM tem grande potencial para contribuir com a gestão de riscos [12]. 
Algumas características e funcionalidades marcantes do BIM, como o suporte à colaboração, a comunicação eficiente, os diversos usos do modelo e as tecnologias que podem ser a ele associadas (sistemas baseados em conhecimento, realidade virtual, GIS, laser scanning, sensores em EPI etc.) trazem grandes benefícios para a GR. Entre esses, vale citar: a facilitação na identificação e monitoramento de riscos; a automação na detecção de conflitos; a melhoria na comunicação dos riscos; a redução de perda de informações; e a melhoria no nível de gerenciamento global [13].

A utilização do BIM na fase de licitação, por exemplo, permite aos licitantes elaborar propostas que abordam a análise dos riscos, em especial os ambientais. Além disso, podem considerar, no plano de obra, a minimização de possíveis efeitos adversos, o que aumenta a efetividade da estratégia de mitigação dos riscos e possibilita a redução do preço da proposta [14].

Dessa forma, considerando que a gestão de riscos tem singular importância para grandes empreendimentos, como, em geral, se caracterizam os de infraestrutura, devido ao seu porte e complexidade [9], o uso do BIM representa um fator vantajoso nesse processo, ao impactar positivamente a qualidade das informações e, por conseguinte, permitir um controle mais eficaz dos riscos [13].

Investigar a percepção dos profissionais sobre como o BIM pode ser associado à GR em empreendimentos de infraestrutura, no cenário do mercado da construção civil nacional, ajuda a entender quais lacunas precisam ser preenchidas e em quais setores, para que ambas as metodologias possam ser mais difundidas e empregadas, em prol do aproveitamento dos seus benefícios e da melhoria contínua da qualidade e eficiência dos empreendimentos brasileiros.

\section{OBJETIVOS}

O objetivo deste trabalho é investigar a percepção dos profissionais sobre o uso do BIM como metodologia para auxílio à gestão de riscos em empreendimentos de infraestrutura. Em especial, busca-se:

- verificar a frequência do emprego do BIM em auxílio à gestão de riscos de empreendimentos de infraestrutura;

- identificar a visão dos profissionais sobre a relevância e os benefícios do BIM nesse emprego; e

- levantar as principais dificuldades no uso do BIM para realizar a GR.

\section{METODOLOGIA}

Foi realizada uma pesquisa exploratória, sob a forma de levantamento com a aplicação de questionário do tipo interseccional [15] a uma amostra composta por: alunos de cursos de especialização em gestão de projetos na construção e de pós-graduação em BIM; profissionais de uma empresa brasileira de engenharia consultiva; profissionais que realizaram curso de especialização em BIM aplicado à implantação de obras de Infraestrutura; e profissionais de um órgão público especializado em projetos. 
O questionário aplicado foi um formulário fechado, organizado em 4 partes (Tabela 1).

Tabela 1: Composição do questionário

\begin{tabular}{lll}
\hline Parte & Escopo & Questões \\
\hline 1 & Perfil dos respondentes (nível de formação, área de atuação e instituição) & $1-4$ \\
2 & Nível de conhecimento e uso do BIM & $5-6$ \\
3 & Nível de conhecimento e adoção da GR & $7-8$ \\
4 & Emprego do BIM para auxiliar a GR, benefícios e barreiras dessa integração & $9-13$ \\
\hline
\end{tabular}

Foi inserido um critério de encerramento automático do questionário quando o respondente apontava que não possuía conhecimentos de gestão de riscos. Esse filtro foi necessário porque as respostas das demais perguntas dependiam de conhecimento pelo menos "básico" nessa metodologia para melhor análise e discussão dos resultados.

\section{RESULTADOS E DISCUSSÕES}

Por conta do critério de encerramento supracitado, dos 88 questionários com respostas iniciadas, 76 foram concluídos. Os resultados foram analisados e categorizados por segmento e tipo de instituição de atuação dos respondentes, procurando focar nas respostas dos profissionais de infraestrutura, em conformidade com o objetivo deste trabalho.

\section{PERFIL DOS PROFISSIONAIS DE INFRAESTRUTURA}

O infográfico abaixo (Figura 1) ilustra o perfil dos profissionais de infraestrutura respondentes ao questionário.

Figura 1: Infográfico referente ao perfil dos profissionais do segmento de infraestrutura

$$
48 \text { por profissionais de infraestrutura }
$$

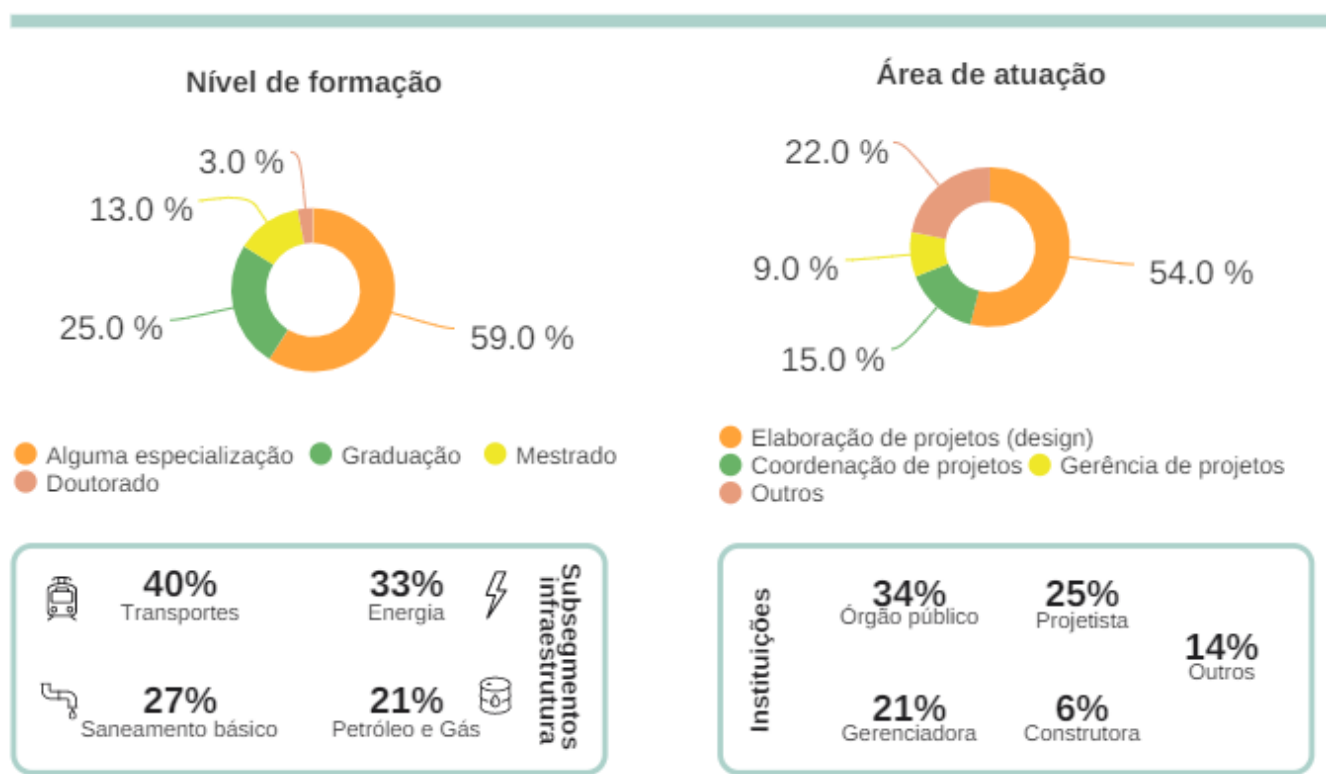

Fonte: os autores. 
Verifica-se que, em sua maioria, os profissionais apresentam grau de especialização adequado para julgar o emprego das metodologias abordadas.

\section{ANÁLISE COMPARATIVA ENTRE SEGMENTOS}

Para analisar as perspectivas entre os diferentes segmentos, foi feita uma comparação entre as partes 2 a 4 do questionário, entre os profissionais que atuam em empreendimentos dos segmentos de edificações e de infraestrutura.

Devido ao critério de encerramento automático do questionário, citado na Metodologia, foi obtido o total de respostas presentes na Tabela 2.

\section{Tabela 2: Controle de questionários}

\begin{tabular}{|c|c|c|}
\hline Questionários respondidos & Edificação & Infraestrutura \\
\hline Iniciado & 39 & 48 \\
\hline Finalizado & 32 & 43 \\
\hline $\begin{array}{l}\text { Descartado devido ao critério de encerramento } \\
\text { automático }\end{array}$ & 7 & 5 \\
\hline
\end{tabular}

Após a análise das respostas, conclui-se que o conhecimento em BIM e em gestão de riscos, da maioria dos profissionais de ambos os segmentos, vai de básico a intermediário (Figura 2), indicando a falta de conhecimento e capacitação dos profissionais como uma possível barreira para a adoção dessas metodologias no Brasil.

Figura 2: Nível de conhecimento em BIM e em gestão de riscos por segmento

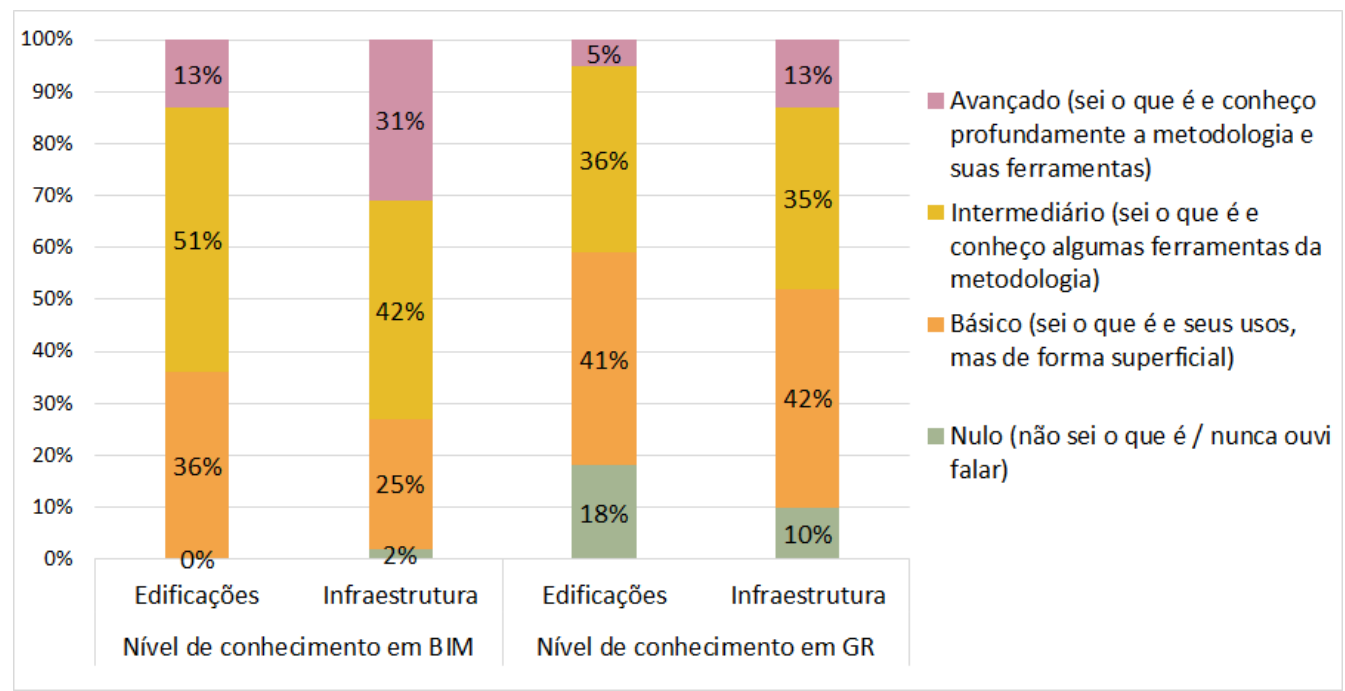

Fonte: os autores.

Observou-se ainda que o índice de utilização do BIM em empreendimentos é superior quando comparado ao de emprego da gestão de riscos (Figura 3). 
Figura 3: Uso da metodologia BIM e emprego da gestão de riscos por segmento

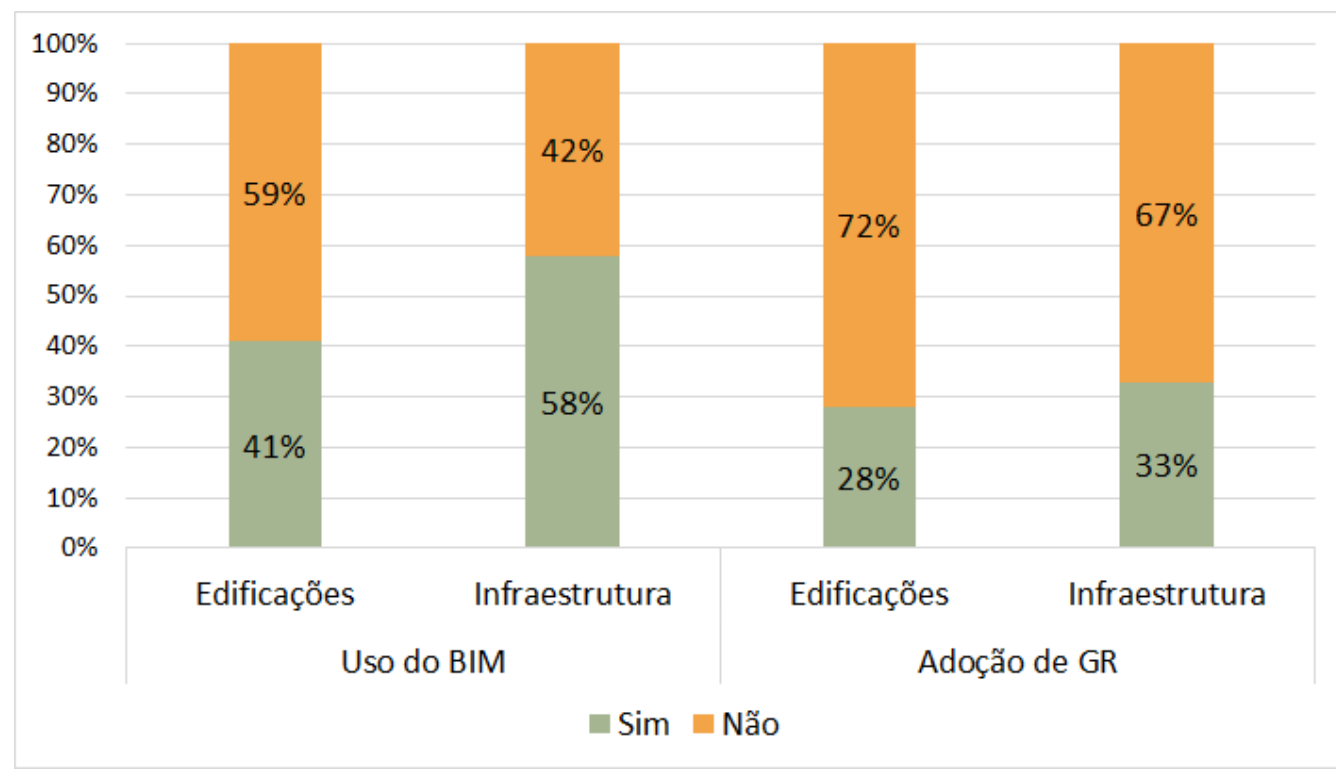

Fonte: os autores.

Apesar do conhecimento e da utilização do BIM estarem mais avançados que a GR, a utilização do BIM para auxiliar o processo de gestão de riscos é incipiente (Figura 4), possivelmente devido ao baixo índice de adoção deste processo (Figura 3).

Figura 4: Uso do BIM para auxiliar na gestão de riscos por segmento

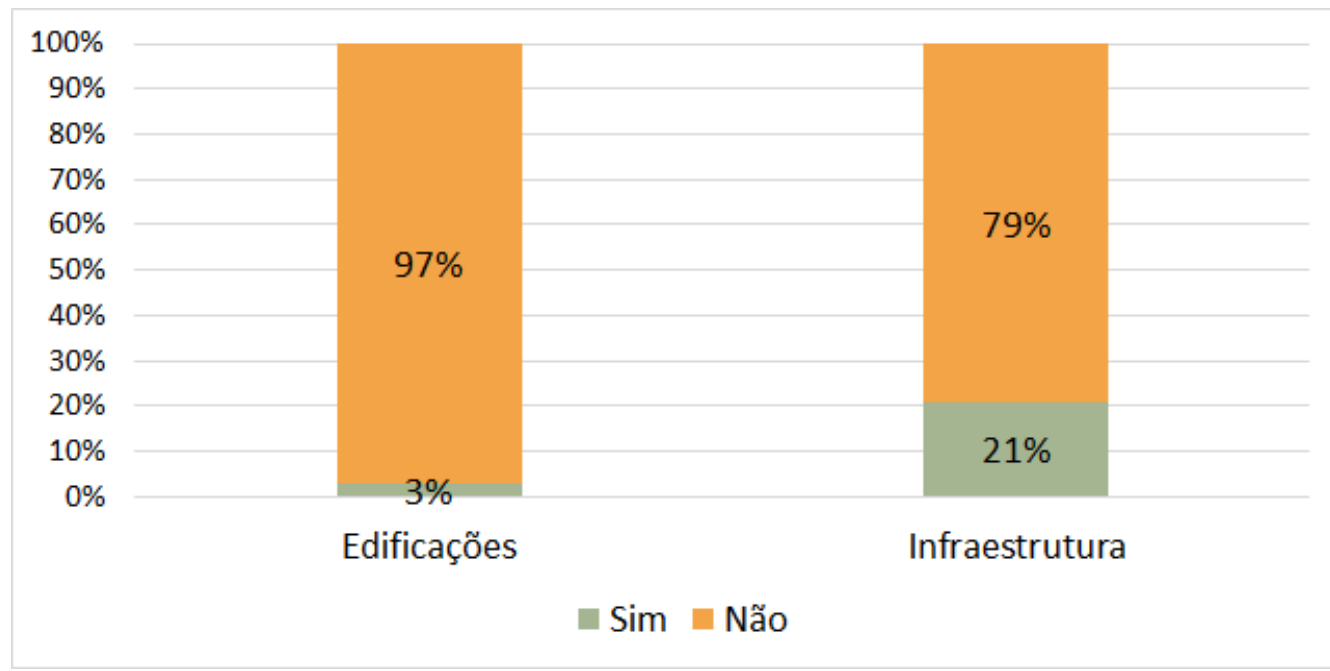

Fonte: os autores.

Quando perguntados o quanto o BIM pode auxiliar o processo de GR, em uma escala de 1 (não auxilia) a 5 (auxilia muito), a média ponderada obtida foi 4,6 para edificações e 4,5 para infraestrutura. Isso mostra que apesar da baixa utilização conjugada das metodologias, os profissionais de ambos os segmentos entendem que o BIM e suas tecnologias associadas têm grande potencial para apoiar a gestão de riscos.

Em relação aos benefícios intrínsecos à implantação de ambas as metodologias, conforme ilustrado na Figura 5, não houve divergência significativa de resultados entre ambos os segmentos, sendo os principais apontados: maior precisão das informações do projeto, maior visibilidade das interferências entre as disciplinas, e melhoria no nível de gerenciamento do empreendimento, reduzindo assim os riscos. 
Figura 5: Principais benefícios do uso do BIM para a gestão de riscos por segmento

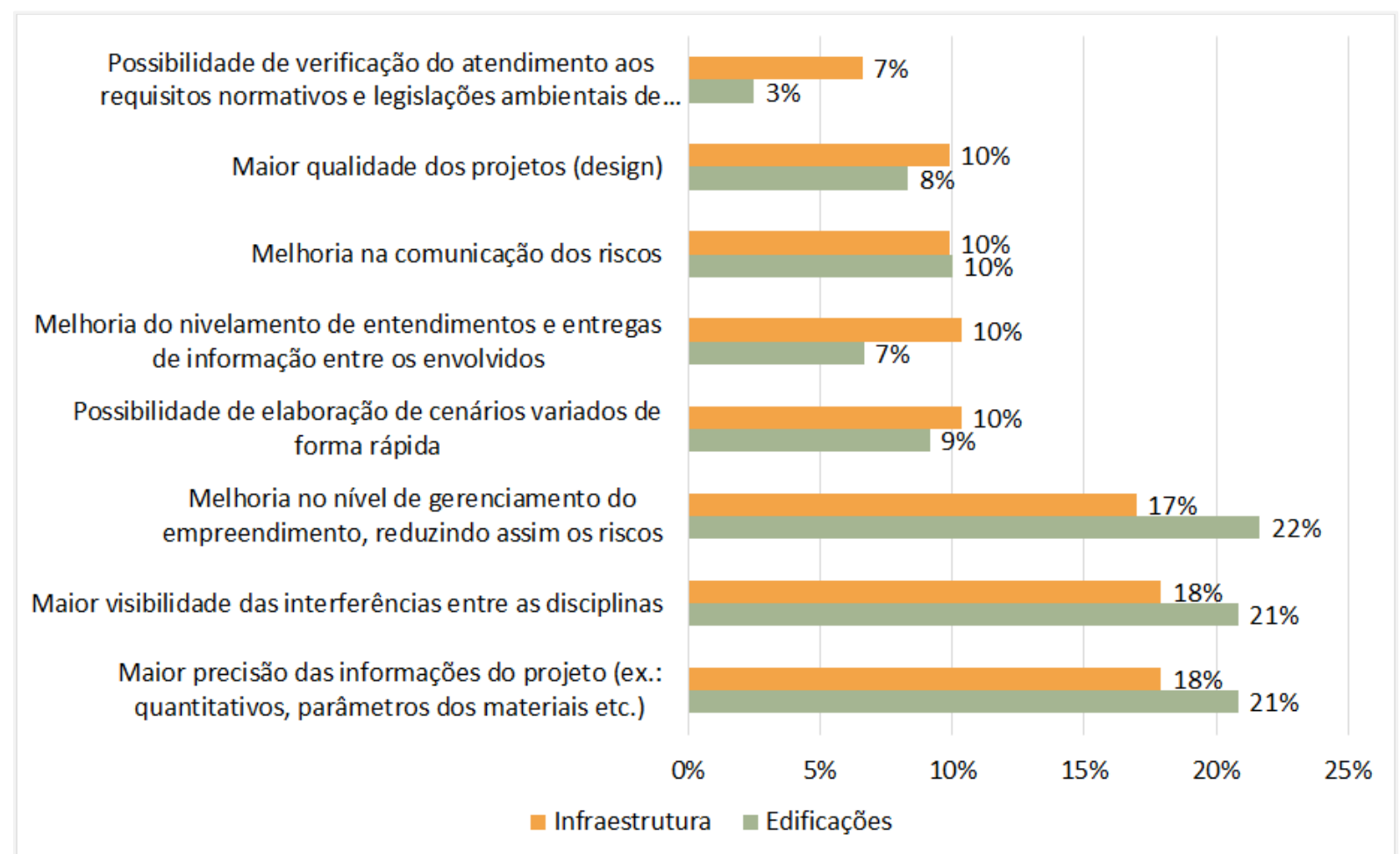

Fonte: os autores.

Quando questionados sobre a capacidade do BIM em favorecer a GR em uma seleção de áreas/atividades, a distribuição das respostas de ambos os segmentos foi semelhante. Contudo, a partir da análise da opção "não tem benefício", os profissionais atuantes no segmento de infraestrutura reconhecem mais benefícios nas áreas/disciplinas "comunicação", "legislação", "ambiental" e "suprimentos", comparativamente aos profissionais de edificações (Figura 6). Esse resultado possivelmente deve-se à maior complexidade, participação de stakeholders e exigências normativas e ambientais às quais os empreendimentos de infraestrutura estão sujeitos em relação aos de edificações. 
Figura 6: Áreas/atividades beneficiadas pelo uso do BIM para a gestão de riscos por segmento

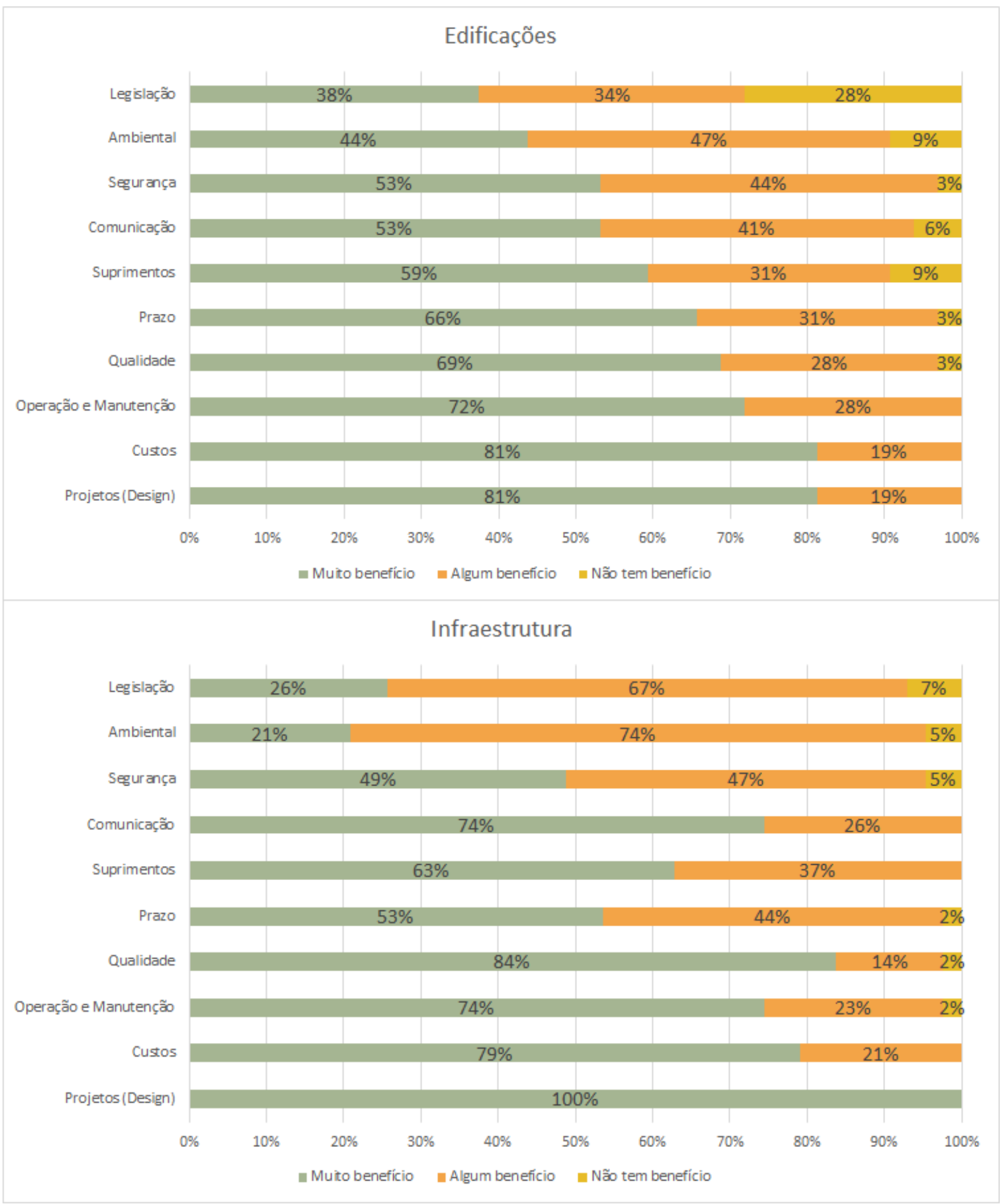

Fonte: os autores.

Em relação às barreiras de implantação, independente do segmento, a falta de conhecimento sobre uma ou ambas as metodologias foi apontada como o principal impeditivo da escalabilidade de utilização do BIM no suporte à GR (Figura 7), evidenciando a necessidade de melhor capacitação dos profissionais para compreensão da importância da qualidade das informações e também qualidade do processo analítico e de tomada de decisão para a gestão de riscos. 
Figura 7: Barreiras para o uso do BIM para a gestão de riscos por segmento

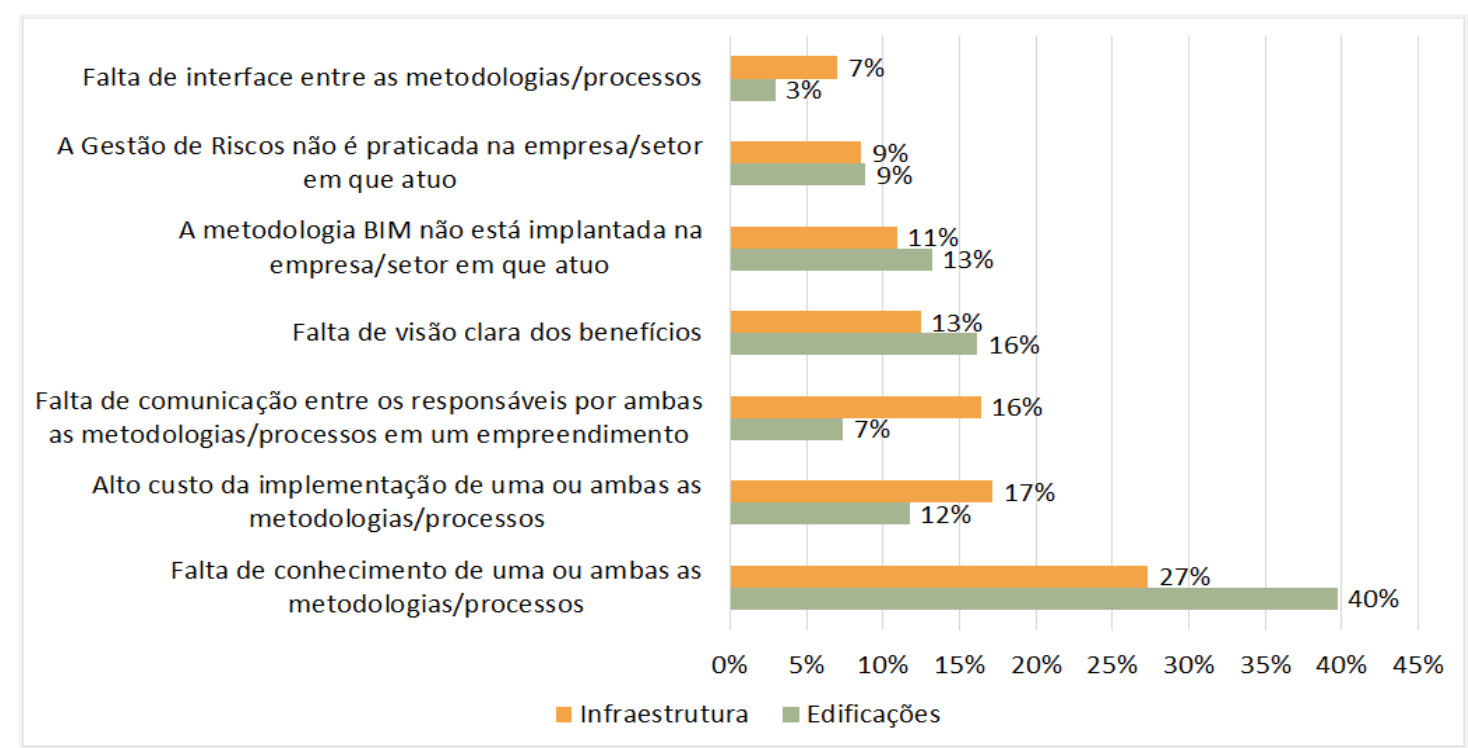

Fonte: os autores.

INFLUÊNCIA DA INSTITUIÇÃO DE ATUAÇÃO

No âmbito do segmento de infraestrutura, analisaram-se as respostas às partes 2 a 4 separadas por instituição de atuação, abordando as três mais representativas no levantamento e considerando o critério de encerramento automático do questionário (Tabela 3).

Tabela 3: Controle de questionários

\begin{tabular}{|c|c|c|c|}
\hline Questionários respondidos & Órgão Público & Projetista & Gerenciadora \\
\hline Iniciado & 16 & 11 & 10 \\
\hline Finalizado & 12 & 11 & 9 \\
\hline $\begin{array}{l}\text { Descartado devido ao critério de } \\
\text { encerramento automático }\end{array}$ & 4 & 0 & 1 \\
\hline
\end{tabular}

Observa-se que o conhecimento em BIM é mais significativo do que o conhecimento em GR (Figura 8). Comparando as instituições, os profissionais de órgão público apresentam menos conhecimento geral tanto de BIM quanto de GR. Os profissionais de empresa projetista apresentam estágio mais evoluído em BIM e algum conhecimento em GR. Já aqueles de gerenciadora despontam com mais conhecimento em ambas as metodologias.

Observa-se na Figura 9 que o emprego do BIM e de gestão de riscos é maior entre os profissionais de empresa projetista e gerenciadora quando comparado aos profissionais de instituição pública. Contudo, o índice geral de implantação da GR é menor do que o de BIM para todas as instituições. 
Figura 8: Nível de conhecimento em BIM e em gestão de riscos por instituição

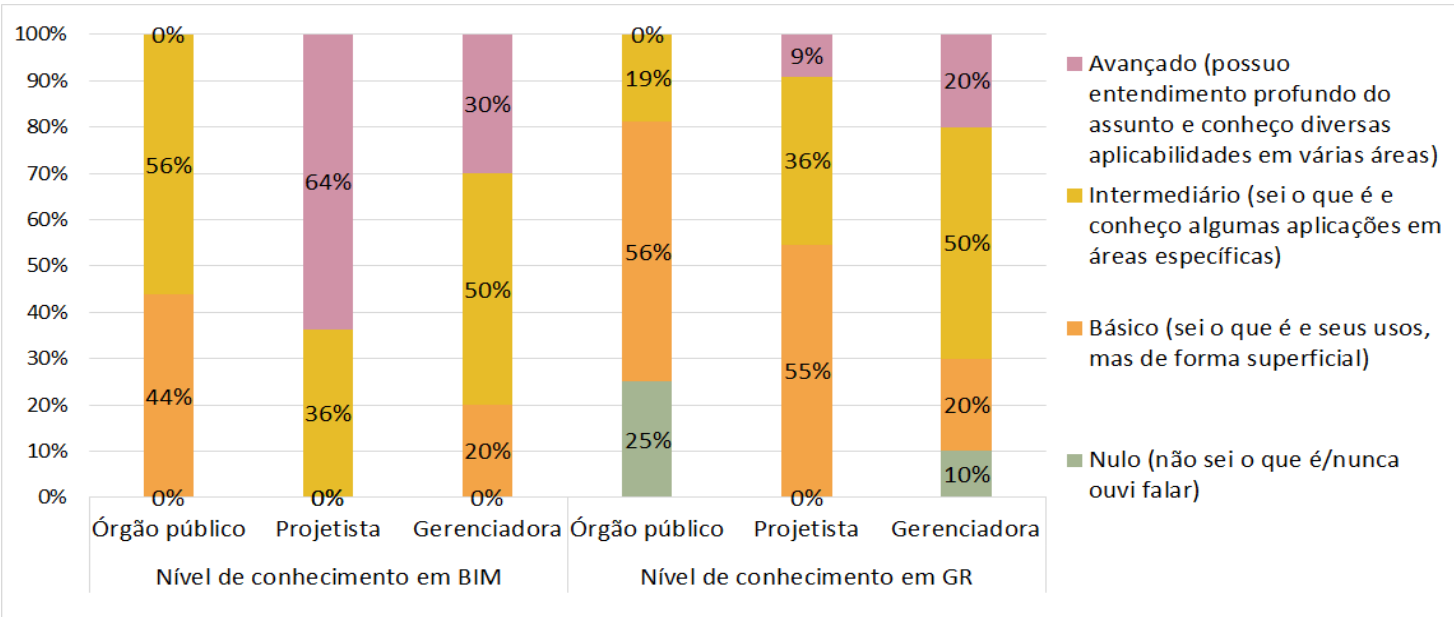

Fonte: os autores.

Figura 9: Uso da metodologia BIM e emprego da gestão de riscos por instituição

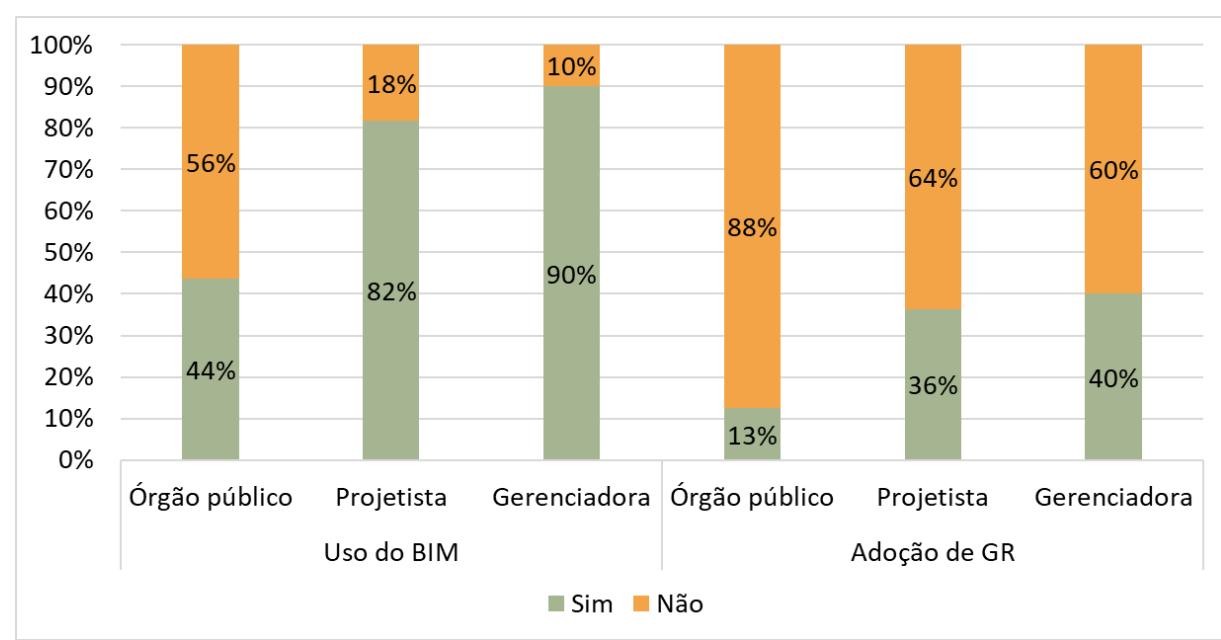

Fonte: os autores.

Com relação ao índice de utilização da metodologia BIM para auxiliar a GR, observa-se um percentual maior daqueles que atuam em gerenciadora (Figura 10), provavelmente devido ao maior conhecimento e emprego de ambas as metodologias.

Figura 10: Uso do BIM para auxiliar na gestão de riscos por instituição

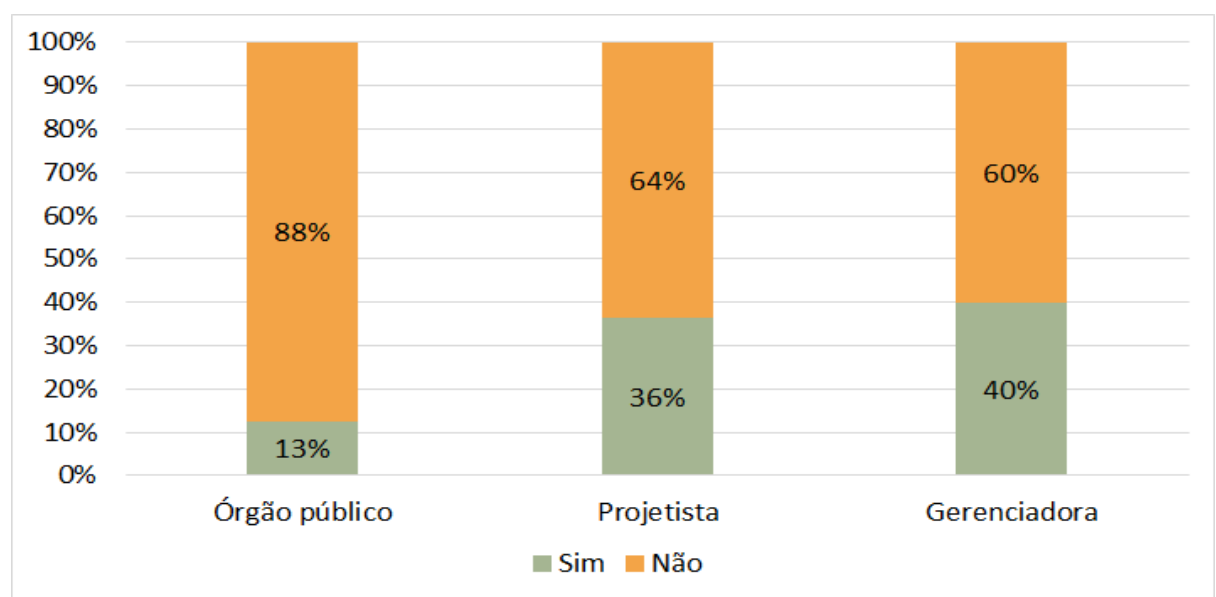

Fonte: os autores. 
Profissionais das referidas instituições avaliaram que, em uma escala de 1 (não auxilia) a 5 (auxilia muito), o uso do BIM pode auxiliar muito a gestão de riscos: órgão público $(4,5)$, projetista $(4,6)$ e gerenciadora $(4,2)$; o que demonstra o reconhecimento da relevância de ambas as metodologias para os empreendimentos.

Para os profissionais das instituições, os itens "maior precisão das informações de projeto", "maior visibilidade das interferências" e "melhoria do nível de gerenciamento" foram vistos como os principais benefícios da utilização integrada de ambas as metodologias (Figura 11).

Figura 11: Principais benefícios do uso do BIM para a gestão de riscos por instituição

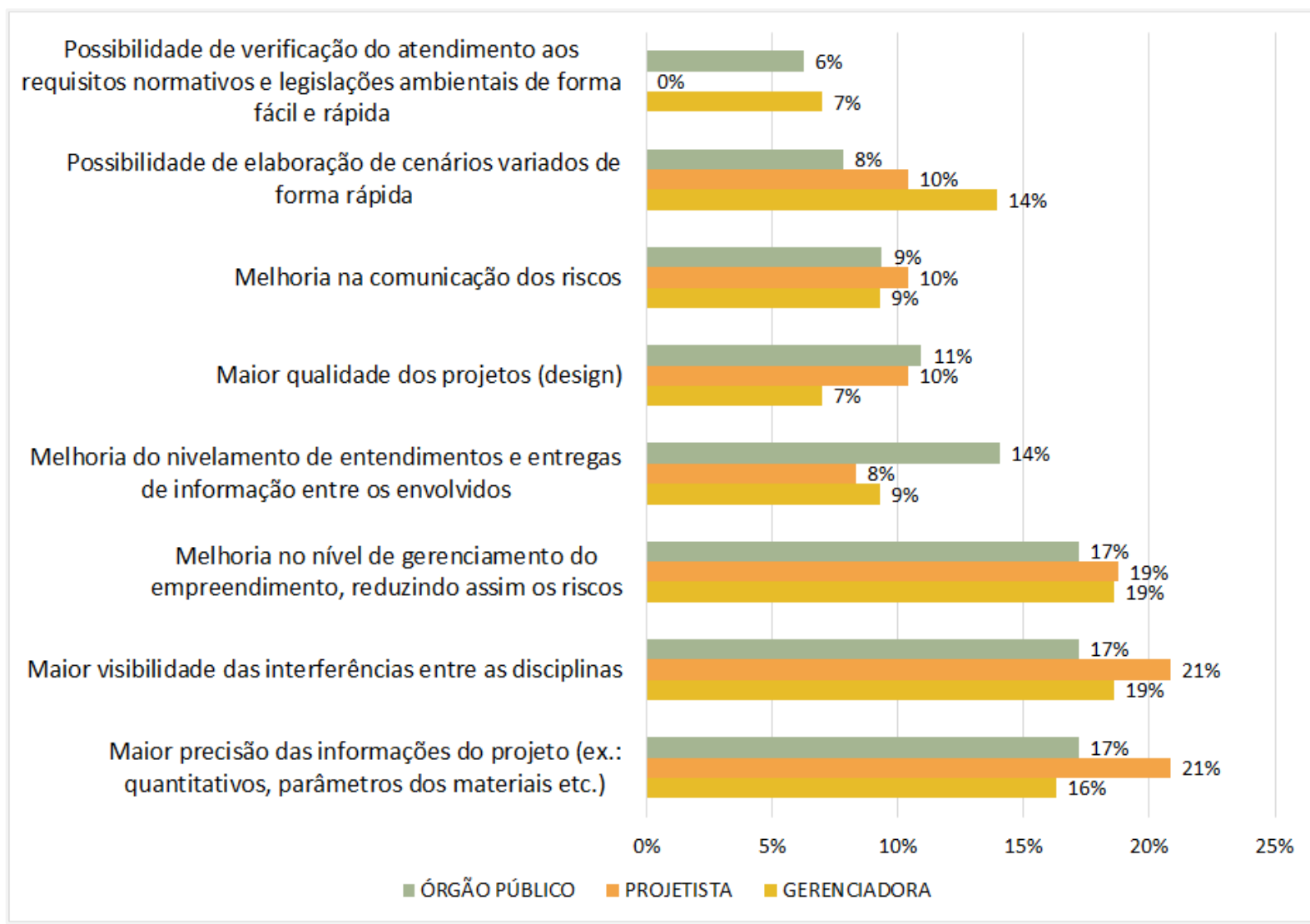

Fonte: os autores.

Os profissionais atuantes em empresas projetistas e órgão público reconhecem benefícios na quase totalidade das áreas/atividades. Os profissionais atuantes em gerenciadoras, por outro lado, indicam mais áreas não beneficiadas. Essas diferenças possivelmente se devem à diversidade de visões desses stakeholders sobre os processos produtivos e de atuação no ciclo de vida dos empreendimentos (Figura 12). 
Figura 12: Áreas/atividades beneficiadas pelo uso do BIM para a gestão de riscos por instituição

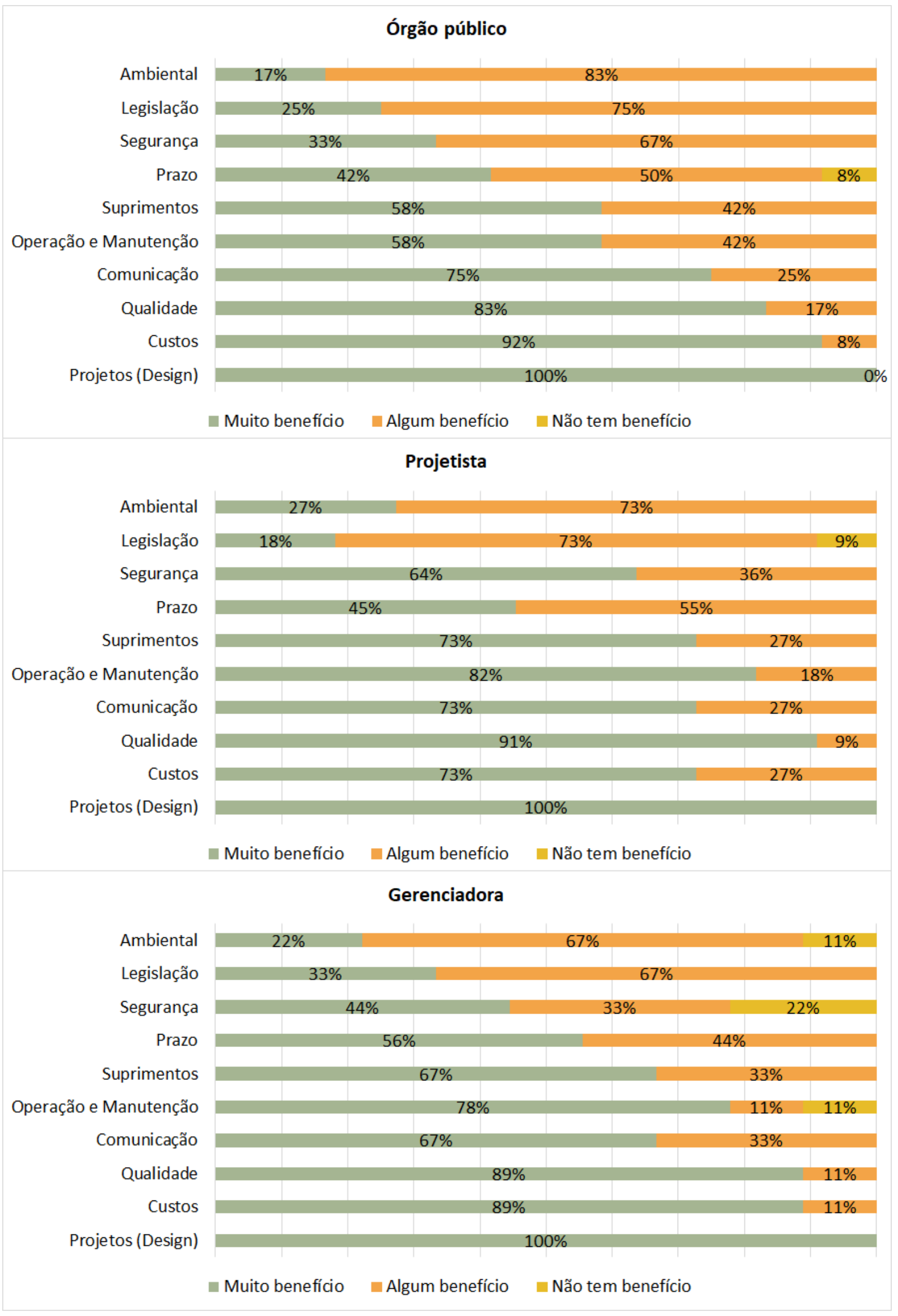

Fonte: os autores. 
A principal barreira vista pelos profissionais atuantes nas instituições em questão foi a falta de conhecimento de uma ou ambas as metodologias/processos (Figura 13). Supostamente, devido ao menor conhecimento em GR (Figura 9), os profissionais não conseguem identificar como o BIM poderia ser integrado ao processo de gestão de riscos. E aqueles de empresa gerenciadora também destacaram a falta de comunicação entre os responsáveis por ambas as metodologias/processos em um empreendimento. Possivelmente, essa avaliação se deve ao papel da gerenciadora de interligar os stakeholders, permitindo-lhe perceber mais claramente como uma comunicação ineficiente interfere na implementação de metodologias que poderiam favorecer a GR.

Figura 13: Barreiras para o uso do BIM para a gestão de riscos por instituição

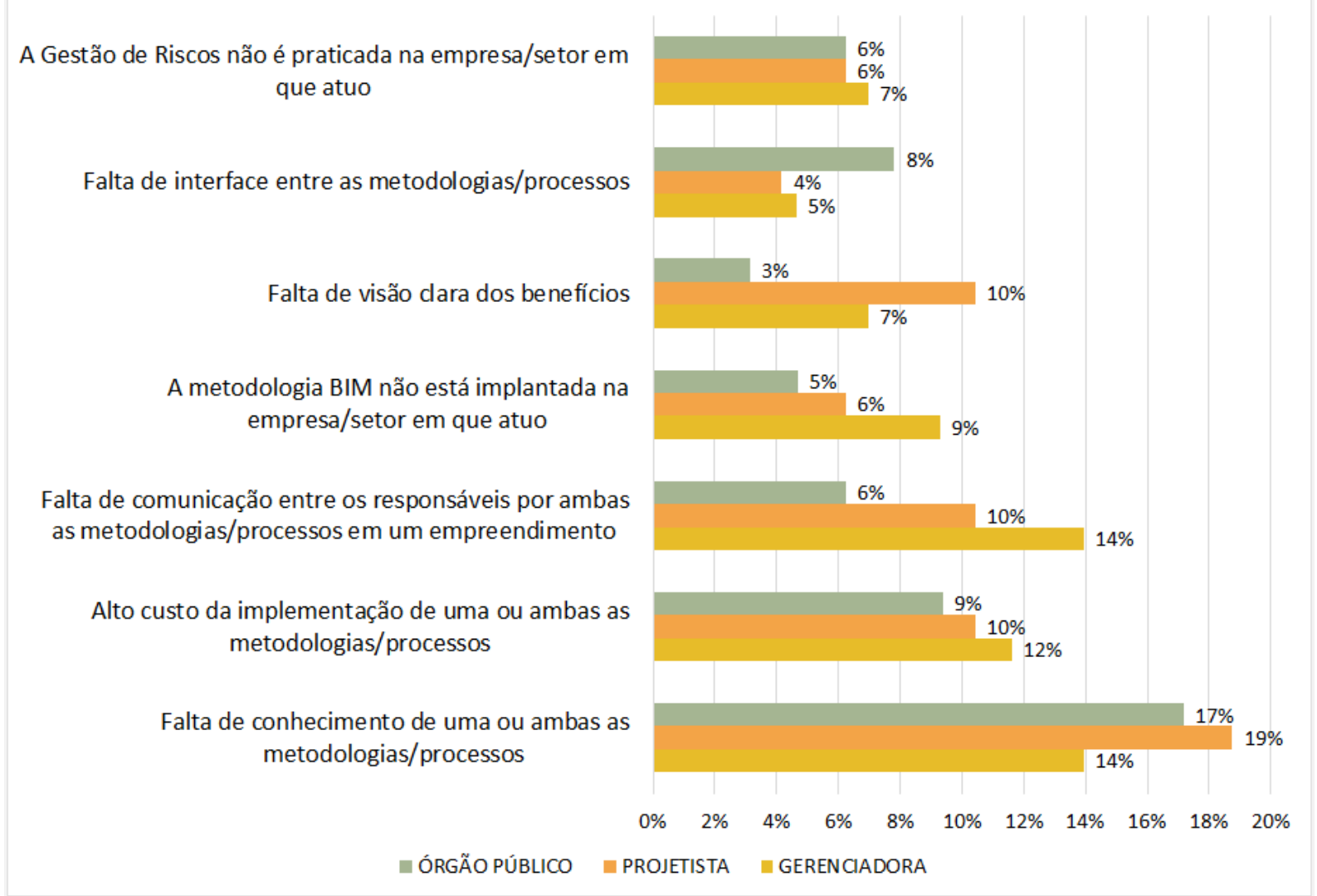

Fonte: os autores.

\section{CONCLUSÃO}

Por meio da revisão da literatura, foi possível verificar pesquisas em desenvolvimento e aplicações práticas que abordam a temática do uso do BIM como suporte à gestão de riscos (GR) em empreendimentos de infraestrutura. O BIM pode apoiar a GR, especialmente ao possibilitar a identificação e avaliação das ameaças e oportunidades do empreendimento, visando mitigar os impactos e as probabilidades de ocorrência de eventos negativos ao negócio, bem como aproveitar-se dos positivos.

O resultado do questionário aplicado evidenciou que o uso do BIM tem sido significativo entre os profissionais da construção civil consultados, especialmente nas empresas que atuam no segmento de infraestrutura, o que chamou atenção por se 
diferenciar das conclusões de outras pesquisas mais heterogêneas sobre o uso do BIM. Entende-se que a razão para essa discrepância foi a seleção de profissionais respondentes para a presente pesquisa, notoriamente aqueles mais envolvidos com a disseminação do BIM em suas empresas/instituições. A amostra provavelmente não representa o perfil médio do profissional do setor; não obstante, as questões colocadas na pesquisa demandam certo nível de conhecimento em GR e BIM.

Foi averiguado que os profissionais de infraestrutura destacaram as áreas "comunicação", "legislação", "ambiental" e "suprimentos" como beneficiadas pelo uso do BIM na gestão de riscos de empreendimentos do segmento, diferentemente daqueles atuantes com edificações.

Constata-se que a gestão de riscos suportada pelo BIM está em um estágio prematuro de aplicação no Brasil, bem como, a existência de limitações que impedem sua disseminação no setor da construção civil, sendo a falta de conhecimento de uma ou ambas as metodologias/processos a principal barreira observada.

A pesquisa permitiu obter um panorama sobre os usos, benefícios e barreiras para implementação das metodologias abordadas, observando-se uma percepção positiva sobre a utilização do BIM em suporte à GR. Nota-se, assim, uma perspectiva otimista de expansão da aplicação conjugada de tais metodologias em empreendimentos de infraestrutura, visando diminuir as incertezas, garantir a qualidade dos produtos e a satisfação dos stakeholders.

Nesse contexto, vale ressaltar a instituição da Estratégia BIM BR [3] e a tendência de aumento da utilização do BIM no curto prazo (até 2 anos) [16]. Em relação à GR, destaca-se a tramitação da nova Lei de Licitações [17], que estabelece a adoção de práticas contínuas e permanentes de gestão de riscos, inclusive mediante o emprego de matrizes de riscos para obras de grande vulto (acima de R\$ 200 milhões), comumente aplicáveis ao segmento de infraestrutura. Assim, as metodologias abordadas podem ganhar representatividade nesse segmento, impactando positivamente a mudança dos cenários apresentados.

Finalmente, sugere-se que novas pesquisas sejam desenvolvidas para: apontar como as instituições devem atuar para implantar o BIM de forma a suportar a gestão de riscos em empreendimentos de infraestrutura; e discutir a correlação entre GR e BIM ao longo do ciclo de vida desses empreendimentos, principalmente nas fases preliminares, quando as premissas e características ainda estão sendo definidas.

\section{REFERÊNCIAS}

[1] BRASIL. Decreto, de 5 de junho de 2017. Institui o Comitê Estratégico de Implementação do Building Information Modelling. Diário Oficial da União, Brasília-DF, 6 jun. 2017.

[2] BRASIL. Decreto no 9.377, de 17 de maio de 2018. Institui a Estratégia Nacional de Disseminação do Building Information Modelling. Diário Oficial da União, Brasília-DF, 18 maio 2018.

[3] BRASIL. Decreto no 10.306, de 2 de abril de 2020. Estabelece a utilização do Building Information Modelling na execução direta ou indireta de obras e serviços de engenharia 
realizada pelos órgãos e pelas entidades da administração pública federal [...]. Diário Oficial da União, Brasília-DF, 3 abr. 2020.

[4] BROCARDO, F.; SCHEER, S. O uso da modelagem da informação da construção 4D (BIM 4D) em projetos de obras militares. In: SIMPÓSIO BRASILEIRO DE TECNOLOGIA DE INFORMAÇÃO E COMUNICAÇÃO NA CONSTRUÇÃO, 1., 2017, Fortaleza. Anais [...]. Fortaleza: UFC, 2017. p. 16-28.

[5] CASTELO, A.; MARCELLINI, L.; VIANA, I. A Construção Digital parte 2. Disponível em: https://blogdoibre.fgv.br/posts/construcao-digital-parte-2. Acesso em 24 jul. 2020.

[6] ASSOCIAÇÃO BRASILEIRA DE NORMAS TÉCNICAS. ABNT NBR ISO 31000: Gestão de riscos - Diretrizes. Rio de Janeiro, 2018.

[7] ZOU, P. X. W.; ZHANG, G.; WANG, J. Understanding the key risks in construction projects in China. International Journal of Project Management, [s. I.], v. 25, p. 601-614, 2007.

[8] LIU, J. Y.; ZOU, P. X. W.; GONG, W. Managing Project Risk at the Enterprise Level: Exploratory Case Studies in China. J. Constr. Eng. Manage, [s.I.], v. 139(9), p. 1268-1274, 2013.

[9] DEY, P. K.; OGUNLANA, S. O. Selection and application of risk management tools and techniques for build-operate-transfer projects. Industrial Management \& Data Systems, [s. I.], v. 104, n. 4, p. 334-346, 2004.

[10] MORANO, C. Análise de risco na estimativa de custo de obras de estruturas metálicas. 2013. Tese (Doutorado em Engenharia Civil) - Universidade Federal Fluminense, Niterói, 2013.

[11] XIA, N.; ZOU, P.; GRIFFIN, M; WANG, X; ZHONG, R. Towards integrating construction risk management and stakeholder management: A systematic literature review and future research agendas. International Journal of Project Management, [s. I.], v. 36, p. 701715, 2018.

[12] AHMAD, Z.; THAHEEM, M.; MAQSOOM, A. Building information modeling as a risk transformer: An evolutionary insight into the project uncertainty. Automation in Construction, [s. I.], v. 92, p. 103-119, 2018.

[13] ZOU, Y.; KIVINIEMI, A.; JONES, S. W. A review of risk management through BIM and BIMrelated technologies. Safety Science, [s. I.], v. 97, p. 88-98, 2017.

[14] SLOOT, R. N. F.; HEUTINK, A.; VOORDIJK, J. T. Assessing usefulness of 4D BIM tools in risk mitigation strategies. Automation in Construction, [s. I.], v. 106, 2019.

[15] BABBIE, E. Métodos de Pesquisas de Survey. Belo Horizonte: Ed. UFMG, 1999, 519 p.

[16] SIENGE; GRANT THORNTON. Mapeamento de Maturidade BIM Brasil. São Paulo, 2020. 84 p. Disponível em: https://www.sienge.com.br/relatorio-mapeamento-de-maturidadebim. Acesso em 05 mar. 2021

[17] BRASIL. Senado Federal. Projeto de Lei no 4253, de 2020. Estabelece normas gerais de licitação e contratação para as administrações públicas diretas, autárquicas e fundacionais da União, dos Estados, do Distrito Federal e dos Municípios. Diário do Senado Federal, Brasília-DF, n. 176, 3 dez. 2020. Disponível em: https://legis.senado.leg.br/sdleggetter/documento?dm=8879045\&ts=1614964331686\&disposition=inline. Acesso em 05 mar. 2021 